\title{
Unfolding the Curriculum: Physical Computing, Computational Thinking and Computational Experiment in STEM's Transdisciplinary Approach
}

\author{
Sarantos Psycharis, Konstantinos Kalovrektis, Eva Sakellaridi, Konstantinos Korres, and Dimitrios \\ Mastorodimos
}

\begin{abstract}
The aim of the present article is to analyze the relation of physical computing with the computational thinking dimensions and the transdisciplinary approach of STEM epistemology in inquiry-based learning environments, when the methodology of the computational experiment is implemented. We argue that computational science and computational experiment can be applied in connection with STEM epistemology, when physical computing activities are embedded in the curriculum for Higher Education students. In order to implement this connection, we present software applications that combine algorithms and physical computing. We believe that engaging students through their existing STEM courses in physical computing - in the form of the computational experiment methodology- is a strategy that is much more likely to succeed in increasing the interest and appeal of STEM epistemology. Different learning modules were designed, which covered the combination of easy java simulations (Ejs) with Arduino and Raspberry pi.
\end{abstract}

Index Terms-Computational Experiment; Computational Thinking; STEM Epistemology; Physical Computing.

\section{INTRODUCTION}

\section{A. Computational Science (CS)}

Computational Science (CS) is the integration of Mathematics, Computer Science and any other discipline to explore "real world" problems. It is defined as a multidisciplinary activity, which brings together concepts from a variety of cognitive subjects [12] and is considered to be part of the Computational Science-Engineering (CSE) community. CS helps learners solve a STEM problem using computational models and this includes tasks like: formulating the problem in a way proper for development of models of simulations, selecting an efficient algorithm; collecting numerical data; analyzing the data obtained; discovering the solution of the problem. One of the essential components of $\mathrm{CS}$ is the transformation of a real phenomenon to an abstract model and its execution as a computational model. This leads us to the notion of the computational experiment (CE), where the model and its

Published on February, 2018

S. Psycharis is Professor of ASPETE and Visiting Professor at Huddersfield University (e-mail: spsycharis@gmail.com).

K. Kalovrektis is a School Teacher (e-mail: kkalovr@gmail.com).

E. Sakellaridi is a Doctoral Researcher at UCL, Institute of Education (e-mail: evangelia.sakellaridi.15@ucl.ac.uk).

$\begin{array}{llllll}\text { K. Korres is a } & \text { School } & \text { Teacher } & \text { (e-mail: } \\ \text { korres.konstantinos@gmail.com). } & & & \\ \text { D. Mastorodimos is a } & \text { School } & \text { Teacher } & \text { (e-mail: }\end{array}$

corresponding simulation "substitute" the "hands-on" experiment [18], [19]. According to Landau et.al. [12], CS suggests the following steps for problem-solving a. Definition of the Problem (from science/real world); b. Modeling the problem (introduction of the mathematical relations between selected variables); c. Selection of the Simulation Method (determination of time dependence of the state variables, selection of discrete, continuous or stochastic processes); d. Creation of the algorithm based on selected numerical analysis methods; e. Implementation of the algorithm in source code (using computer languages); and $\mathrm{f}$. Evaluation of the results and comparison with real data.. Later on, when we will discuss computational thinking (CT), it will be quite apparent that CS shares many commonalities with CT and may serve as the background platform to implement didactic models that include the dimensions of CT and STEM epistemology.

\section{B. Computational Thinking (CT)}

Jeanette Wing [24] introduced the term 'computational thinking' (CT) in an article published in Communications of the ACM. CT involves solving authentic problems, designing systems and understanding human behavior by drawing on the concepts fundamental to computer science. Despite this extensive interest, successful CT integration in education still faces unresolved issues and challenges [9]. According to the literature, CT includes: abstraction, algorithmic thinking, decomposition, debugging, pattern recognition and generalization [1], [3].

\section{The inquiry-based teaching and learning approach}

Inquiry-based learning is considered as a didactic model for improving the teaching and learning of STEM disciplines [6] and can be defined as the process of identifying problems, reviewing experiments, selecting alternatives, designing investigations, developing conjectures, searching for data, developing models, communicating with peers and constructing consistent arguments [5]. Bell et al. [4], identified nine main science inquiry processes, that could be used in inquiry-based STEM disciplines, namely: orienting and asking questions; generating hypotheses; planning; investigating; analyzing and interpreting; exploring and creating models; evaluating and concluding; communicating; predicting. The nine inquiry tools of Bell et al. [4] are connected to the essential features of Inquiry [2], namely: Question (Learner engages in scientifically oriented questions); Evidence (Learner gives priority to data collection); Analysis (Learner analyses the data to form evidence); Explain (Learner develops 
explanations from evidence); Connect (Learner connects explanations to scientific knowledge); Communicate (Learner communicates and justifies explanations); and Reflection (Learner engages in metacognitive experiences).

\section{The Computational Experiment (CE) approach combined with Inquiry-Based teaching and learning approach}

In order to effectively implement the inquiry-based learning as a didactic model, Klahr \& Dunbar [11], introduced two "spaces", the hypothesis and the experimental spaces. Psycharis [20] added one more space, the "prediction space", in order to introduce the process of modeling and the comparison of data produced by the model with real data taken from a simulation or from a physical computing activity. In the "prediction space", the CS methodology is implemented through the development of models of simulations that include all or some of the dimensions of the "Computational Thinking (CT)". According to Psycharis [18],[19]), the three spaces of the CS methodology should include dimensions from CT, namely: logically collecting, organizing and analyzing data; representation of data in forms suitable for analysis and exploration, development of abstract models, creation of simulations; and algorithmic thinking (a series of ordered steps) as they are also suggested by the International Society for Technology in Education (ISTE) and the Computer Science Teachers Association (CTSA) (http://www.iste.org/docs/ct-documents/computationalthinking-operational-definition-flyer.pdf?sfvrsn=2, Last Access, 31 May, 2016).

In this context, the three spaces of the CS methodology include:

1) The hypotheses space, where the students -usually under the guidance of the teacher-state the hypotheses of the problem to be studied, as well as the variables included in the problem and the possible relations between the variables.

2) The experimental space, which includes the "numerical" model and the method of simulation for the problems under study. In this space, the learners are engaged in the scientific method writing their models, according to the variables selected and the interaction laws (e.g. from Physics) that govern the phenomenon. In this space, students collect the data from their model and analyze them; while they attempt to connect their explanations with the theory they have been taught.

3) The prediction space, where the results, conclusions or solutions formulated in the experimental space, are compared with the analytical (Mathematical) solution, as well as with data from the real world. Students would also make logical arguments about the generalization of their results and whether the results have been impacted by their hypothesis and the variables they have chosen. Generalization is closely linked to one of the dimensions of CT.

In Table 1I, we propose an interrelation between the spaces of the CE and the features and the tools of inquiry.

\section{E. STEM epistemology}

STEM methodology follows the so-called

transdisciplinary approach, which focus on the "integrated" approach to teach the four disciplines included in the STEM cognitive areas. According to Kelley \& Knowles [10], STEM methodology includes: Situated Learning; the Engineering Design and Making; the Scientific Inquiry and the Mathematical Thinking and Logical Thinking, as an integrated system. A pedagogy referred to as "Purposeful Design and Inquiry" (PD\&I), is considered as an important component of integrative STEM education. PD\&I pedagogy combines technological design and making with the inquiry based learning, engaging students in inquiry, situated in the context of the problem-solving process [22].

TABLE I: THE INTERRELATION OF THE CE SPACES, THE INQUIRYMETHOD FEATURES AND THE INQUIRY TOOLS

\begin{tabular}{lll}
\hline \hline $\begin{array}{l}\text { Spaces of the } \\
\text { Computational } \\
\text { Experiment [20] }\end{array}$ & $\begin{array}{l}\text { Essential Features } \\
\text { of Inquiry [2] }\end{array}$ & Inquiry tools [4] \\
\hline Hypotheses space & Question & $\begin{array}{l}\text { Orienting and asking } \\
\text { questions; generating } \\
\text { hypotheses }\end{array}$ \\
\hline & Evidence Analyze & $\begin{array}{l}\text { Planning-Investigating } \\
\text { Analysis and } \\
\text { interpretation }\end{array}$ \\
& Explain & $\begin{array}{l}\text { Modeling } \\
\text { Experimental space }\end{array}$ \\
\hline \hline
\end{tabular}

\section{F. Physical Computing}

Recently, education researchers have adapted the term physical computing and they are now using it in a wider meaning. Specifically, they consider physical computing as a way to use computers to collect data received by the physical/real world [13]. Physical computing can be implemented in computer science by using it in order to teach computer science concepts [16]. Physical computing is considered as a proper tool in order to combine digital elements with the real world, as it develops a communication between the physical world and the digital world of the computer [23]. Physical computing takes the computational concepts into the real phenomenon so that the student can use them in an authentic environment Physical computing activities are strongly connected to the dimensions of CT, namely: abstraction; algorithmic thinking; automation; decomposition; debugging; and generalization.

\section{G. Physical Computing: unplugged, making, tinkering and remixing}

According to Namukasa et al. [14], there are four pedagogical stages of learning in order to think computationally when learners are engaged in physical computing, namely: (1) unplugged; (2) making; (3) tinkering; and (4) remixing (or "hacking"). Unplugged activities can be implemented without the use of computers and can be used to engage in CT dimensions (e.g. abstraction), as well as to enhance subject knowledge, often embedding and augmenting computer science concepts into the curriculum [8]. These constructivist activities are often kinesthetic in nature and make abstract concepts both tangible and visible [8].

Making is a technical term used to refer to activities of 
individuals or groups of people who, inspired by technology, "work" with things, make things, take things apart and want to develop things that solve problems. In making, they engage in practices, such as prototyping and testing products, methodologies used by engineers. Digital making can be used to engage students in CT dimensions, such as sequencing, recursion, decomposition and debugging [17].

When mentioning about tinkering, Papert [15] described learning as consisting of building up a set of materials and tools that one can handle and manipulate. The main idea of tinkering is to encourage students to use materials as tools to represent/implement the dimensions of CT. Commonly and widely used and known computer programming software for children and novices, useful for tinkering, are: the Scratch (https://scratch.mit.edu/), Scratch for Arduino (http://s4a.cat/), Ardublock (http://blog.ardublock.com/) and Easy Java Simulations (Ejs). Arduino and Raspberry pi platforms are also considered as essential tools to implement tinkering. These can enable students to easily see the connection between changes in the program and the corresponding changes in the data received from the physical model/real world. Activities can be created that need the implementation of an algorithm and the development of programming in order to guide a robot through an obstacle course or programming the Arduino or Raspberry pi to reveal specific patterns.

TABLE II: A MODEL FOR THE CONNECTION BETWEEN CT, CE AND PHYSICAL COMPUTING

\begin{tabular}{lll} 
& PHYSICAL COMPUTING & \\
\hline \hline Spaces of the & Essential Features of & Inquiry tools \\
Computational & Inquiry - & \\
Experiment & Physical Computing- & \\
& Dimensions of CT & \\
\hline Hypotheses space & Essential Features of & Orienting \\
& Inquiry & and asking \\
& Question & questions; \\
& Physical Computing & generating \\
& Unplugged activities & hypotheses \\
& Dimensions of CT & \\
& Abstraction, & \\
decomposition & \\
\hline \hline
\end{tabular}

Lastly, Remixing involves proficiency in examining a source code with a critical eye, as well as modifying, debugging and manipulating the code to adjust it to new situations. When students are engaged in coding, they develop their creative thinking by proposing new solutions and alternatives. Scratch can be used for remixing, since, according to Resnick et al. [21], community members are constantly borrowing, adapting and building on one another's ideas, images, and software programs. Physical computing covers the design, making and implementation of interactive objects and allows students to develop concrete products and artefacts of the real world, which are in alignment with the dimensions of CT. Physical computing can be used in STEM education as an educational activity, grounded in students' interests and creativity.

H. Computational Science, Inquiry-based approach, Computational Thinking and Physical Computing in STEM epistemology. An integrated model

We will now propose an integration of the CE, the physical computing, the STEM epistemology and the dimensions of $\mathrm{CT}$ and present our results in a form of a Table (Table II).

\section{MATERIALS AND DiDACTIC ACTIVITIES}

\section{A. Software and Materials used}

Here, we will present some experiments-activities that connect the CE, CT and Physical computing using in some examples the software Ejs (http://www.um.es/fem/EjsWiki/). Easy Java simulation (Ejs) software does not demand knowledge of the programming language Java and its interface is not difficult for use, since it resembles the interface the students have met in traditional lectures embedded with specific tools to write down mathematical expressions. Arduino (https://www.arduino.cc/) is an open hardware platform that is becoming increasingly popular within the education community. The creators of Arduino designed a very easyto-use platform and due to its open-source nature, it is supported by a massive user community who share their ideas, projects and solutions. Raspberry pi is an open hardware platform that can be used to control physical objects, while it has the advantage to operate as computer and not only as controller (as Arduino does).

\section{B. Didactic Activities}

\section{1) Visualization of Sorting algorithms (Activity 1)}

Given that students face difficulties with the concepts of the "variable" and the algorithm, researchers have turned their focus on the "use" of CT to resolve such proplems. CT poses an important question to researchers: What are the proper ways to teach fundamental computing concepts to students? Visualization is suggested as one way of supporting student learning [7]. In this activity, we will use Ejs to help students understand the sort algorithms using the visualization capacity provided by the "view" element of Ejs. You can visit the link (http://www.opendiscoveryspace.eu/edu-object/algorithmostaxinomisis-fysalidas-me-ti-hrisi-ejss-848384, Last Access 15 June 2017) to explore and download the algorithm and the source code for the visualization of the bubble sort algorithm. This application was developed by one of the authors (Psycharis) and an MSc student (Mastorodimos Dimitrios). Initially, we presented the video to students (as an unplugged activity) about Hungarian dance and its connection to bubble sort algorithms in order for them to make hypotheses about the way the sorting algorithms work. This activity also enhances the abstraction dimension of students. At the next phase (the experimental phase), we developed the source code in Ejs, in order to connect Ejs with Arduino. The algorithm and part of the source code developed are presented below. The reader can find the algorithm and the source code at this link: http://www.opendiscoveryspace.eu/en/edu-

object/algorithmos-taxinomisis-fysalidas-me-ti-hrisi-ejss848384

During the experimental phase of the CE, students used the essentials features of inquiry-based teaching approach (evidence, analysis, explanation), the algorithmic thinking of CT and they participated in the development of the source code. For the physical computing part, they had to classify 
in order $20 \mathrm{CDs}$ and they tried to reproduce the steps of the algorithm, in order to sort the CDs according to the algorithm. At the prediction phase, they communicated their result and they tried to find examples to generalize their code. They proposed examples of sorting from real life, like the Hungarian dance (Fig. 1).

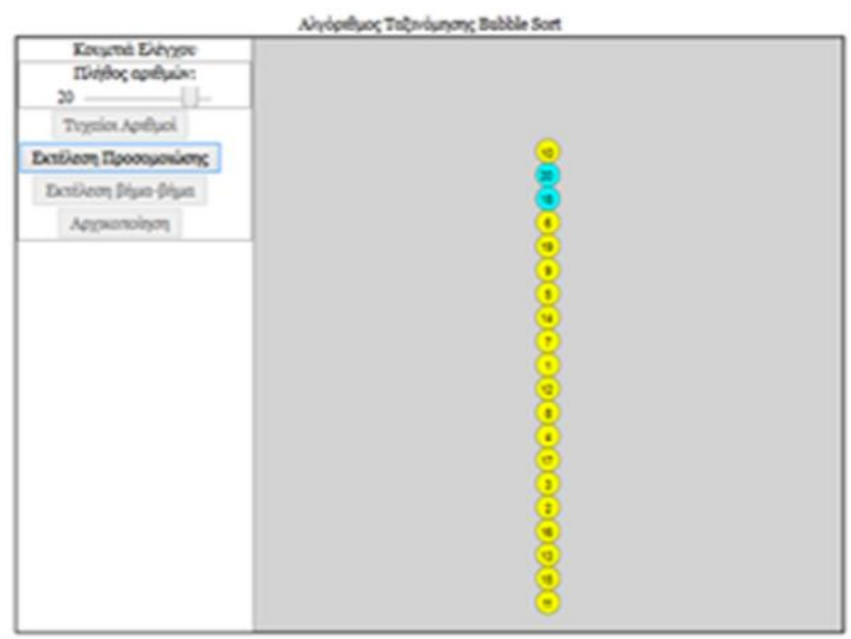

Fig. 1. The running of the model. During the running colors were changed according to the comparison between them

\section{2) Control of LED using Ejs and Arduino (Activity 2)}

In this activity, students controlled a LED using Ejs (Fig. 2).

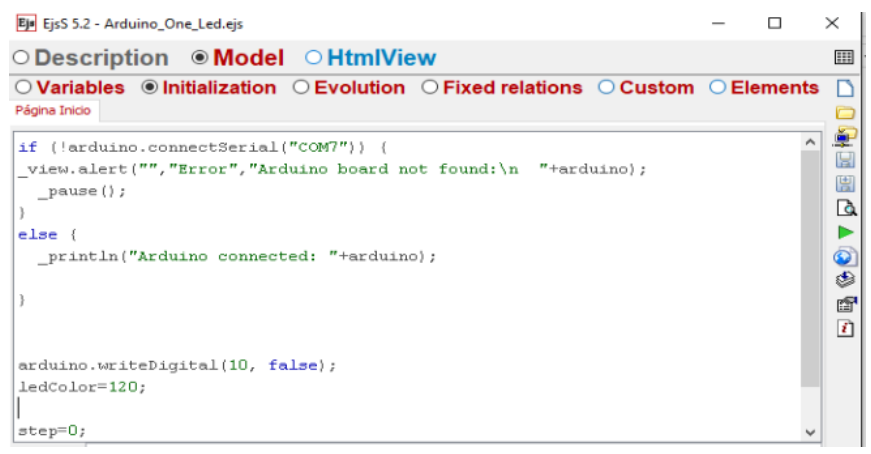

Fig. 2. Connection of Ejs with Arduino

In this activity, students were engaged in many dimensions of physical computing (i.e. design/making) and in almost all dimensions of CT. For example, they used the CT concept of abstraction when they thought about the possibility to switch on a LED remotely, the design of the circuit; the algorithmic thinking and the generalization (for example, how we can extend this simple example in order to control traffic lights). We also presented the same application using the Scratch for Arduino, where the control of the LED is done from the keyboard (Fig. 3).

1) Activity 3

In this application, we used the Raspberry pi in order to control the motion of four graphical elements using Scratch (Fig. 4).

2) Activity 4

This activity is an unplugged activity. Students were asked to construct (design and make) the following robotic arm (Fig. 5).
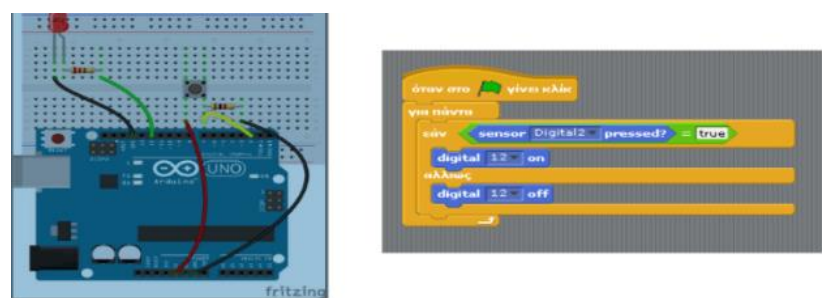

Fig. 3. Control of the LED from the keyboard using Scratch4A(http://s4a.cat/)

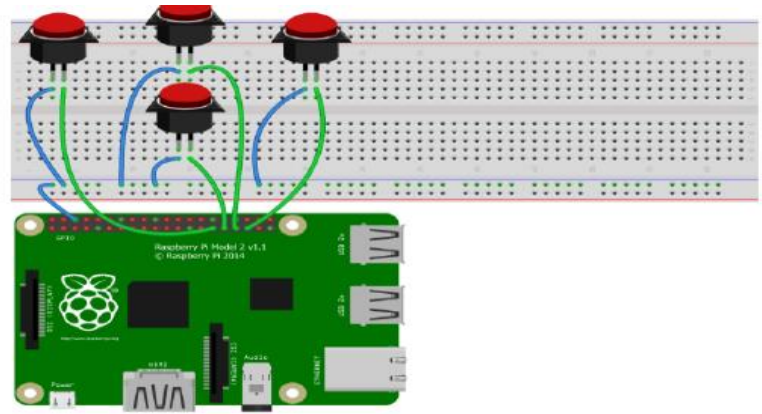

Fig. 4. A simple video game using Raspberry pi

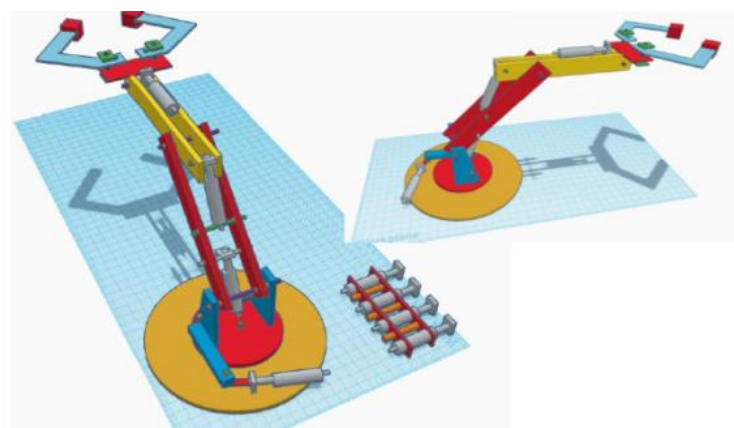

Fig. 5. An unplugged activity

During the activity, students had to be engaged in the features of the inquiry-based teaching and learning approach and the physical computing activities (design/make). Students also had the chance to be engaged in CT dimensions, as they had to think in abstraction for the different parts of the arm, to decompose the system and use logical reasoning to explain its motion.

\section{PRELIMINARY RESUlTS -DisCUSSION}

We focused on physical computing, which involves building interactive physical systems, which can sense and respond to the measurements received from the Analog world. We then developed applications created by Raspberry Pi and Arduino and controlled by Ejs or Scratch. This work proposes a model that combines the phases of the $\mathrm{CE}$ with the dimensions of $\mathrm{CT}$ and the dimensions of physical computing. We implemented -as a preliminary work- the above activities to postgraduate students, who study for their MSc degree in STEM, and prospective trainee teachers. We followed the qualitative approach and in the future, we aim to extend our research to a bigger sample with quantitative tools like a questionnaire for CT. After the instructional intervention, eight students were selected for semi-structured interviews. The results showed that the intervention based on the visualization method resulted in significantly better acquisition of sorting concepts. The qualitative data analysis indicated that 
students constructed proper abstractions through their engagement in visualization algorithmic activities, mainly due to Activity 1. All students expressed the view that framing the activities in the three phases of the computational experiment and organizing the tasks in each phase for CT and physical computing, made them more organized and they considered that this connection was also helpful in their preparation for organizing a lesson plan. Students felt that in the experimental phase of the CE, they had a lot of degrees of freedom to develop the dimensions of CT (mainly the logical reasoning, he development of algorithm and decomposition) and also that they could propose the design of artefacts. Some students expressed the view that sometimes unplugged activities can form a good guideline to understand the physical process before they try to transfer the problem in computing. All students considered the above activities as a good starting point and they continued their work developing new applications connecting Scratch or Ejs with Arduino and Raspberry. For example, one such activity can be found at: http://portal.opendiscoveryspace.eu/edu-object/heat-

transfer-conduction-monitoring-tool-844601, which studies the transfer of heat using Arduino and Ejs. Another artifact was based on the Balak Ram theorem (http://page.mi.fuberlin.de/bhrnds/publ_papers/behrends_humble.pdf).

The authors of this study argue that students' active engagement in inquiry-based activities that combine the CT and physical computing dimensions in a CE setting, could help them increase their self-efficacy and internal motives for STEM epistemology (work in progress). Another research in progress is related to a quantitative research of: "What effects does physical computing have on the dimensions of computational thinking, when the transdisciplinary approach is implemented in inquiry based learning environments?"

\section{REFERENCES}

[1] C. Angeli, J. Voogt, A. Fluck, M. Webb, J. Malyn-Smith and J. Zagami, "A K-6 Computational Thinking Curriculum FrameworkImplications for Teacher Knowledge," Educational Technology \& Society, vol. 19 no. 3, pp. 47-57, 2016.

[2] L. D. Asay, and M.K. Orgill, "Analysis of essential features of inquiry found in articles published in The Science Teacher, 1998-2007,' Journal of Science Teacher Education, vol. 21, pp. 57-79, 2010.

[3] V. Barr and C. Stephenson, "Bringing Computational Thinking to K12: What Is Involved and What Is the Role of the Computer Science Education Community?" ACM Inroads, vol. 2, no.1, pp. 48-54, 2010.

[4] T. Bell, D. Urhahne, S. Schanze, and R. Ploetzner, "Collaborative inquiry learning: models, tools and challenges," International Journal of Science Education, vol. 32, no. 3, pp. 349-377, 2010.

[5] P.L. Bell, C. Hoadley, and M.C. Linn, "Design-based research as educational inquiry," in Internet environments for science education, Eds. M.C. Linn, and P.L. Bell, Mahwah, NJ: Lawrence Erlbaum Associates, 2004

[6] R. W. Bybee, L.W. Trowbridge, and J.C. Powell, Teaching Secondary School Science: Strategies for Developing Scientific Literacy, New Jersey Merrill, 2008.

[7] I. Cetin, and C. Andrews-Larson, "Learning sorting algorithms through visualization construction," Computer Science Education, vol. 26 , no. 1 , pp. $27-43,2016$

[8] P. Curzon, "cs4fn and computational thinking unplugged," WiPSE '13. Proceedings of the 8th Workshop in Primary and Secondary Computing Education, pp. 47-50, 2013.

[9] European Commission. Developing Computational Thinking in Compulsory Education. JRC SCIENCE FOR POLICY REPORT [Online]. Available: http://publications.jrc.ec.europa.eu/repository/ bitstream/JRC104188/jrc104188_computhinkreport.pdf, 2016
[10] T.R. Kelley, and J.G. Knowles, "A conceptual framework for integrated STEM education," International Journal of STEM Education, vol. 3 no. 11, 2016.

[11] D. Klahr, and K. Dunbar, "Dual space search during scientific reasoning. Cognitive Science," vol. 12, pp. 1-48, 1998.

[12] R.H. Landau, J. Paez, and C. Bordeianu, A Survey of computational physics: introductory computational science, New Jersey: Princeton University Press, 2008.

[13] S. Libow Martinez, and G. Stager, Invent to Learn - Making, Tinkering, and Engineering in the Classroom, Torrance, CA: Constructing Modern Knowledge Press, 2013.

[14] I.K. Namukasa, D. Kotsopoulos, L. Floyd, J. Weber, Y.B. Kafai, and S. Khan, "From computational thinking to computational participation: Towards achieving excellence through coding in elementary schools,', in: Math + coding symposium, ed G. Gadanidis. London: Western University, 2015.

[15] S. Papert, Mindstorms: Children, computers, and powerful ideas, New York: Basic Books, 1980.

[16] M. Przybylla, and R. Romeike, R, "Physical computing and its scope - towards a constructionist computer science curriculum with physical computing," Informatics in Education, vol. 13, no. 2, pp. 225-240, 2014.

[17] M. Przybylla, and R. Romeike, "Physical computing in computer science education," Proceedings of the $9^{\text {th }}$ Workshop in Primary and Secondary Computing Education. Berlin, Germany. November 5-7, pp. 136-137, 2014.

[18] S. Psycharis, "Inquiry-based computational experiment, acquisition of threshold concepts and argumentation in science and mathematics education," Journal of Educational Technology \& Society, vol. 19, no. 3, 2016.

[19] S. Psycharis, "The impact of computational experiment and formative assessment in inquiry-based teaching and learning approach in STEM education," Journal of Science Education, and Technology, vol. 25, no. 2 , pp. 316-326, 2015

[20] S. Psycharis, "The effect of the computational models on learning performance, scientific reasoning, epistemic beliefs and argumentation," Computers \& Education, vol. 68, pp. 253-265, 2013.

[21] M. Resnick, J. Maloney, A. Monroy-Hernandez, N. Rusk, E Eastmond, and K. Brennan, K., "Scratch: Programming for all," Communications of the ACM, vol. 52, no. 11, pp. 60-67, 2009.

[22] M. Sanders, "A rationale for new approaches to STEM education and STEM education graduate programs," presented at the 93rd Mississippi Valley Technology Teacher Education Conference, Nashville, TN, 2006.

[23] S. Schulz, and N. Pinkwart, N., Physical Computing in STEM Education [Online]. Available: https://cses.informatik.huberlin.de/pubs/2015/wipsce/physical-computing-in-stemeducation.pdf, 2016

[24] J. M. Wing, "Computational thinking and thinking about computing," Communications of the ACM, vol. 49, pp. 33-35, 2006.

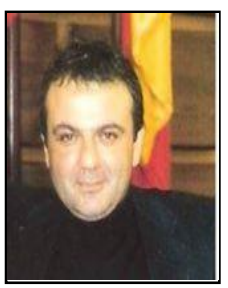

Sarantos Psycharis was born in Canada , 1961, He holds a PhD in Computational Physics (University of Glasgow,1989), Msc in Information Technology(University of Athens,2002) and Bsc in Physics(University of Athes,1983) .His Scientific interests focus on Applications of Computational Science and STEM in Education/Didactics.

$\mathrm{He}$ is PROFESSOR at ASPETE (School of Pedagogical and Technological Education, Athens, Greece) and VISITING PROFESSOR at

Huddersfield University, UK.

Currently he has published the articles

Psycharis, S., (2016).'Inquiry Based- Computational Experiment, Acquisition of Threshold Concepts and Argumentation in Science and Mathematics Education". Journal "Educational Technology \& SocietyVolume 19, Issue 3, 2016

Psycharis, S. (2016). 'The Impact of Computational Experiment and Formative Assessment in Inquiry Based Teaching and Learning Approach in STEM Education" Journal of Science Education,25(2),316-326 and Technology (JOST) DOI 10.1007/s10956-015-9595-z.

Psycharis, S. ,Kalia, M.(2017). The Effects of Computer Programming on high school students' problem solving, reasoning skills and self-efficacy in Mathematics; ,Instructional Science, 45(5), 583-602 10.1007/s11251017-9421-5

Professor Psycharis is President of the Helelnic Education Society of STEM Education(www.e3stem,edu.gr 


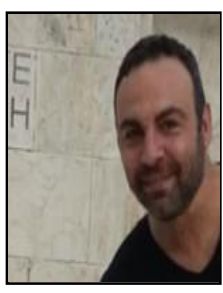

Konstantinos Kalovrketis holds a $\mathrm{PhD}$ in Computer Science at Univestiry of Piraeus, MA in Education and MSc in Embedded System. He is PostDoc at University Of Thessaly, Department of Informatics Science in subject 'Stem for girls'. He works as PD407 Lecturer at the University of Thessaly at Department of Informatics Science. He has published many research papers in international scientific journals, and in international conferences, $\mathrm{He}$ is author and co-athor in more than 10 academic books.

$\mathrm{He}$ is a reviewer in many international scientific journals and has participated in many international conferences as a member of the Scientific Committee. He is member editor on International Journal of Research Studies in Science, Engineering and Technology [IJRSSET], Education and Science (http://eduscience-uth.weebly.com/ ISSN 25852310), and more others. His research interests include; ICT in education; STEAM education; development hardware/software IoT (Internet of Thinks) for STEM, Pedagogical curriculum development and instruction.

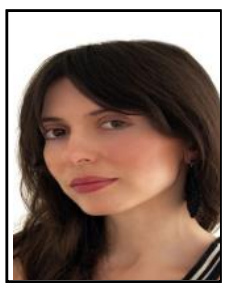

Eva Sakellaridi holds an MA in Education from the University of Bath, UK (2014) and is currently a doctoral researcher at UCL, Institute of Education, UK.

She works as an online Lecturer at the University of South Wales, UK and as a freelance Education Consultant.

Her research interests include leadership and management; ICT in education; curriculum development and instruction; STEM education.

Miss Sakellaridi is a member of BERA and BELMAS

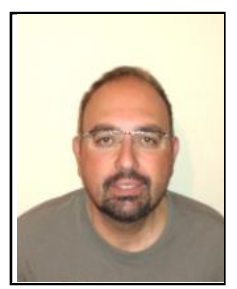

Dr Korres Konstantinos is an Adjunct Lecturer at the Department of Education of ASPETE and the Department of Philosophy Pedagogy and Psychology of the University of Athens .

Dr Korres Konstantinos has studied Mathematics at the Department of Mathematics of the University of Athens, holds an MSc in Didactics and Methodology of Mathematics from the Department of Mathematics of the University of Athens and a PhD in Didactics of Mathematics and Sciences using New Technologies from the Department of Statistics and Insurance Sciences of the University of Piraeus.

He has been teaching in Higher Education as an Adjunct Lecturer since 2008. He has been teaching courses at ASPETE in the postgraduate programs MSc in Science, Technology, Engineering and Mathematics (STEM), MA in Education, MA in Education Sciences, in the Pedagogical Training Program (EPPAIK) and in the Counselling and Guidance Program
(PESYP). He has also been teaching at the University of Athens in the postgraduate program MSc in Counselling and Vocational Guidance and in the Certificate of Pedagogical and Teaching Competence (PPDE). Also he has been teaching in Secondary Education as a Mathematics teacher since 2005

His research interests include amongst others Didactics of Mathematics and Sciences, STEM Education, Research Methods in Education, Quantitative research methods and methods of Statistical Analysis and Psychometry. He has published many research papers at international journals, he has presented many papers at international conferences and he is the co-author of two books. He is a reviewer at many international journals and he has participated in many international conferences as a member of the scientific committee. He is a member of the board of the Professional Body of Hellenic Education Society of STEM (E3STEM).

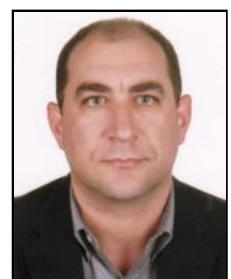

Dimitrios Mastorodimos received a BSc degree in Computer Science from University of Ioannina, Greece in 2000, a MSc degree in Computer Science from Staffordshire University, UK, in 2007, and a MSc degree in STEM in Education from A.S.PE.T.E., Greece in 2017.

He worked as an IT teacher in secondary education in Greece for 11 years and he is currently working as an IT teacher in Special Primary School Herakleion Attica. His research interests include algorithms; STEM education and Intelligent Tutoring Systems. 